\title{
MUSCLE VARIATIONS IN THE TIBIA OF SEVERAL SPECIES OF APHIDS
}

\author{
By Forrest W. Miller \\ Department of Zoölogy, University of Pittsburgh
}

Uichanco $^{1}$, who has studied the muscles and movement of the tarsus of Myzus persicx, states that there is a single extensor muscle which moves the tarsus. He concludes that this condition holds for all species of aphids. Weber ${ }^{2}$ reviews the same idea set forth by Uichanco and also gives this condition as generally occurring among the aphids.

A study of several species of aphids shows that there are some variations from the above stated generality. This variation occurs in the number of extensor muscles and, where there is a single muscle, within the muscle itself.

In all the species used for study, several specimens were stained with eosin and mounted in balsam, others were unstained and mounted in euparol. With both of these methods the muscles show up very well after the specimen has cleared. Both alate and apterous forms were included in the study. Examination of mounted material was made under the high power of the microscope $(440 \mathrm{x})$, and of live material under the binocular microscope $(50 \mathrm{x})$.

The following species were examined: Aphis sambucifolii, Aphis rumicis, Aphis feminea, Amphorophora cosmopolitania, Eriosoma lanigerum, Drepanaphis acerifolii, Colopha ulmicola, Macrosiphum granarium and Schizoneura americana.

All of these species are characterized by the absence of the flexor muscle ${ }^{3}$. In none of them was the writer able to

${ }^{1}$ Uichanco, L. Muscles and Movement of Tarsus of Aphids. Psyche, Vol. 28, 1921.

${ }^{2}$ Weber, H. Biologie der Hemipteren. Springer, Berlin, 1930.

${ }^{3}$ The muscles and the parts of the legs are named with respect to the appendage when in its natural position. 
determine the presence of a proximal elongation of the first tarsal segment, for the insertion of the extensor muscle, as described by Uichanco. The extensor muscle is inserted directly on the endo-proximal edge of the first tarsal segment as may be seen in the drawings. In some cases (Fig. F) this muscle arises on the proximal end of the tibia, where there are two points of origin, one on the endoproximal, and the other on the ecto-proximal wall of the segment. From this origin the muscle passes outward through the segment as a very thin tendon-like muscle. Just before the insertion on the tarsus, however, this muscle becomes very wide and again abruptly narrows down into a tendonous insertion on the first tarsal segment. (Figs. A, G.) This muscle is called the extensor by Uichanco.

A second muscle (extensor) appearing in the species studied, is very short and much wider than the first muscle mentioned. This one arises on the lateral wall of the tibia, slightly distad from a point midway between the proximal and distal ends of the segment. From this origin, which is rather wide, the muscle passes out to the tendon-like insertion on the endo-proximal edge of the first tarsal segment.

The combination of the above mentioned muscles has been observed in Colopha ulmicola, Aphis rumicis and Amphorophora cosmopolitania. (Figs. A. D.) In some cases the extensor muscle which arises in the proximal end of the tibia is absent. In this case a short muscle, similar to the second extensor muscle mentioned, replaces it. This is found in Aphis sambucifolii, Drepanaphis acerifolii and Aphis feminea. (Figs. B, H.) A further variation is found in the muscles of Eriosoma lanigerum. Here there are four small extensor muscles. (Fig. E.)

The function of the missing flexor muscle is taken over by "the tension of the wall of the tibia." 1 The fulcrum upon which the tarsus moves is located at the ecto-distal end of the tibia. (Fig. G.) The first tarsal segment increases slightly in width from the proximal to the distal end. When the extensor muscle contracts, it draws the first segment of the tarsus into the cavity of the tibia, and thus, since the tarsus is of slightly increasing greater width, a tension is

${ }^{1}$ All quotations are from Uichanco. 


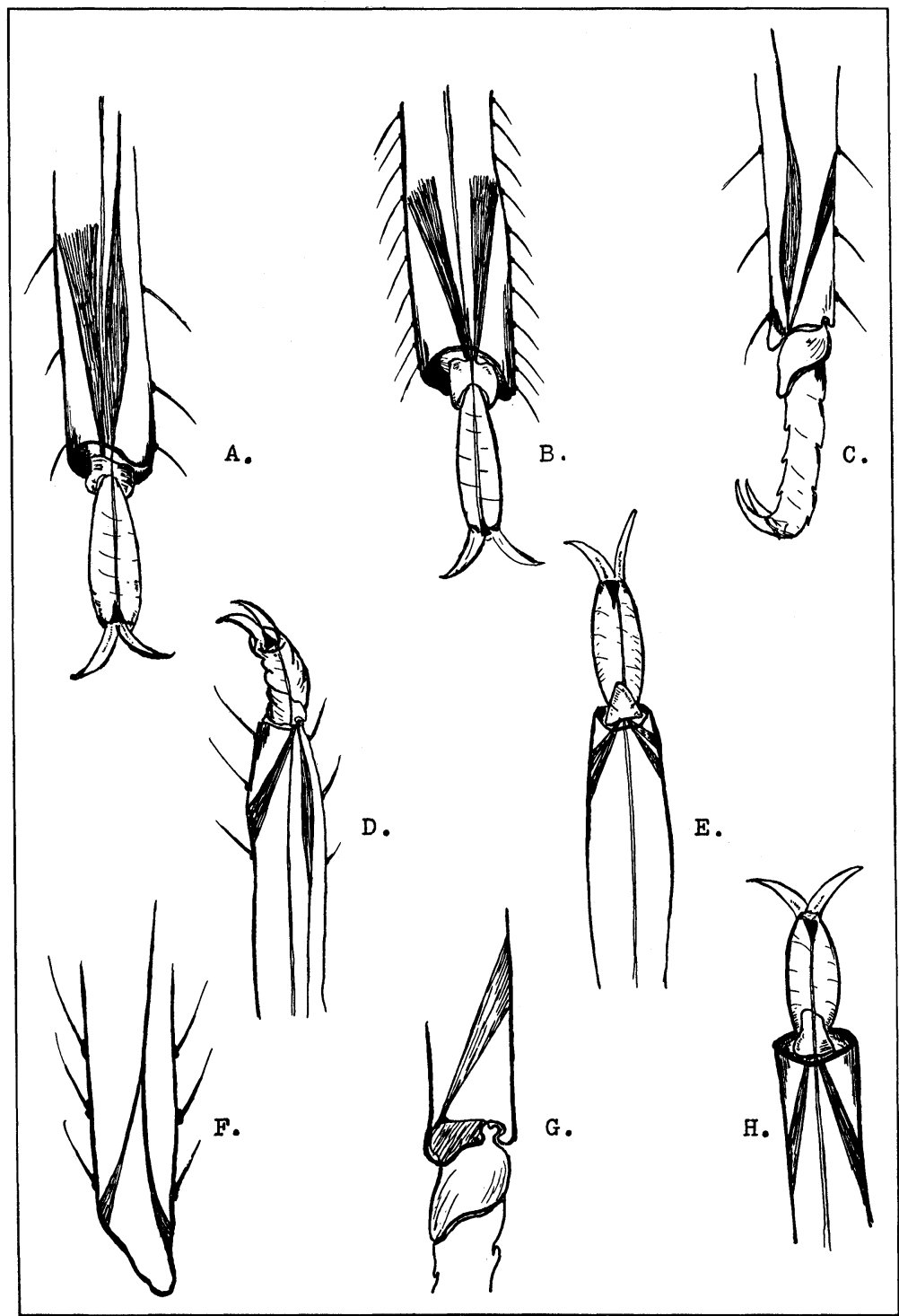

Miller-Tibial Muscles of Aphids. 
placed on the wall of the tibia. "It appears that the wall of the tibia performs the function of the lost antagonistic muscle of the tarsus of aphids." No articular membrane could be seen.

Species represented on Plate II.
A. Aphis rumicis
B. Aphis feminea
C. Drepanaphis acerifolii
D. Colopha ulmicola
E. Eriosoma lanigerum
F. Schizoneura americana
G. Articulation of tarsus and tibia (diagrammatic)
H. Aphis sambucifolii 

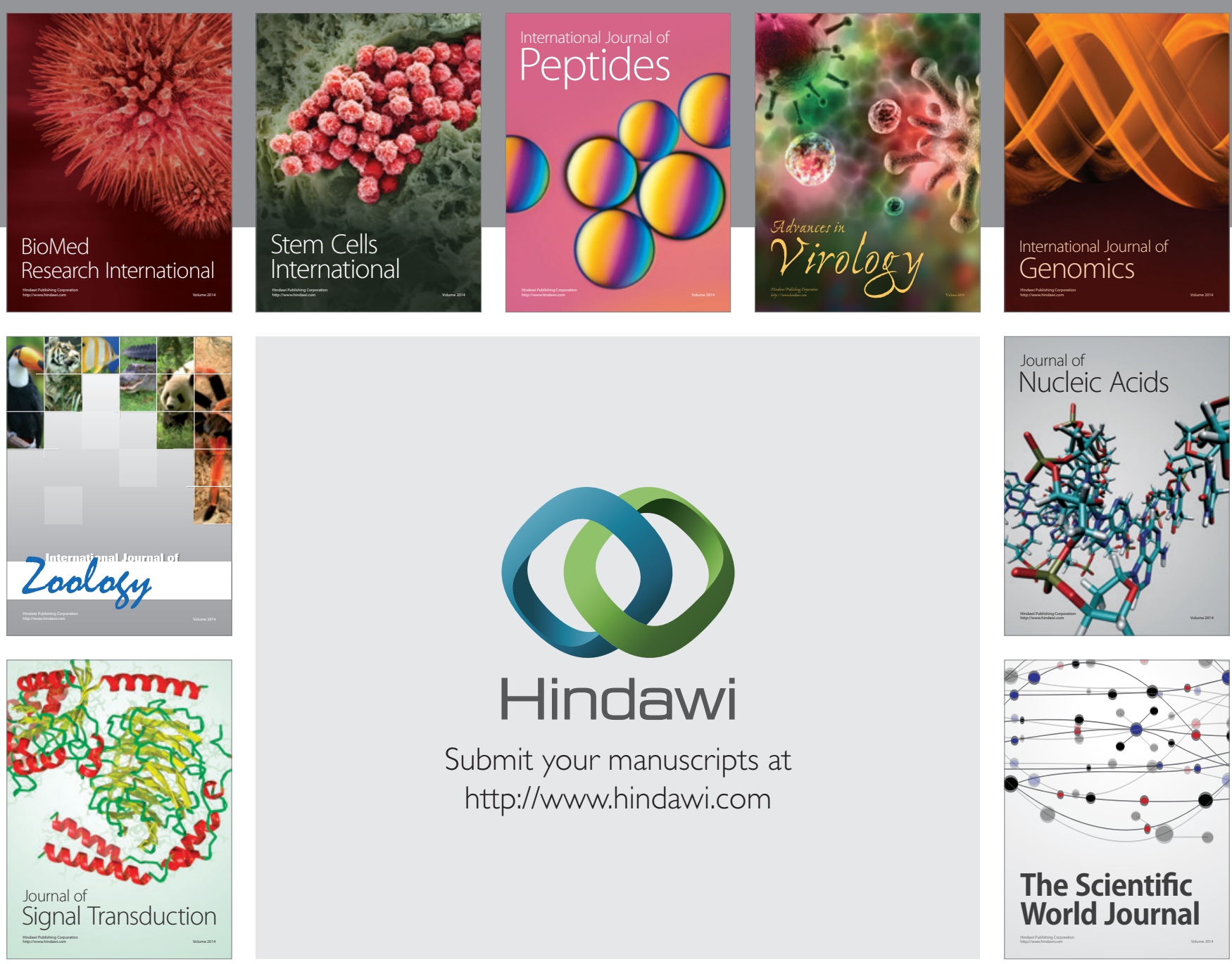

Submit your manuscripts at

http://www.hindawi.com
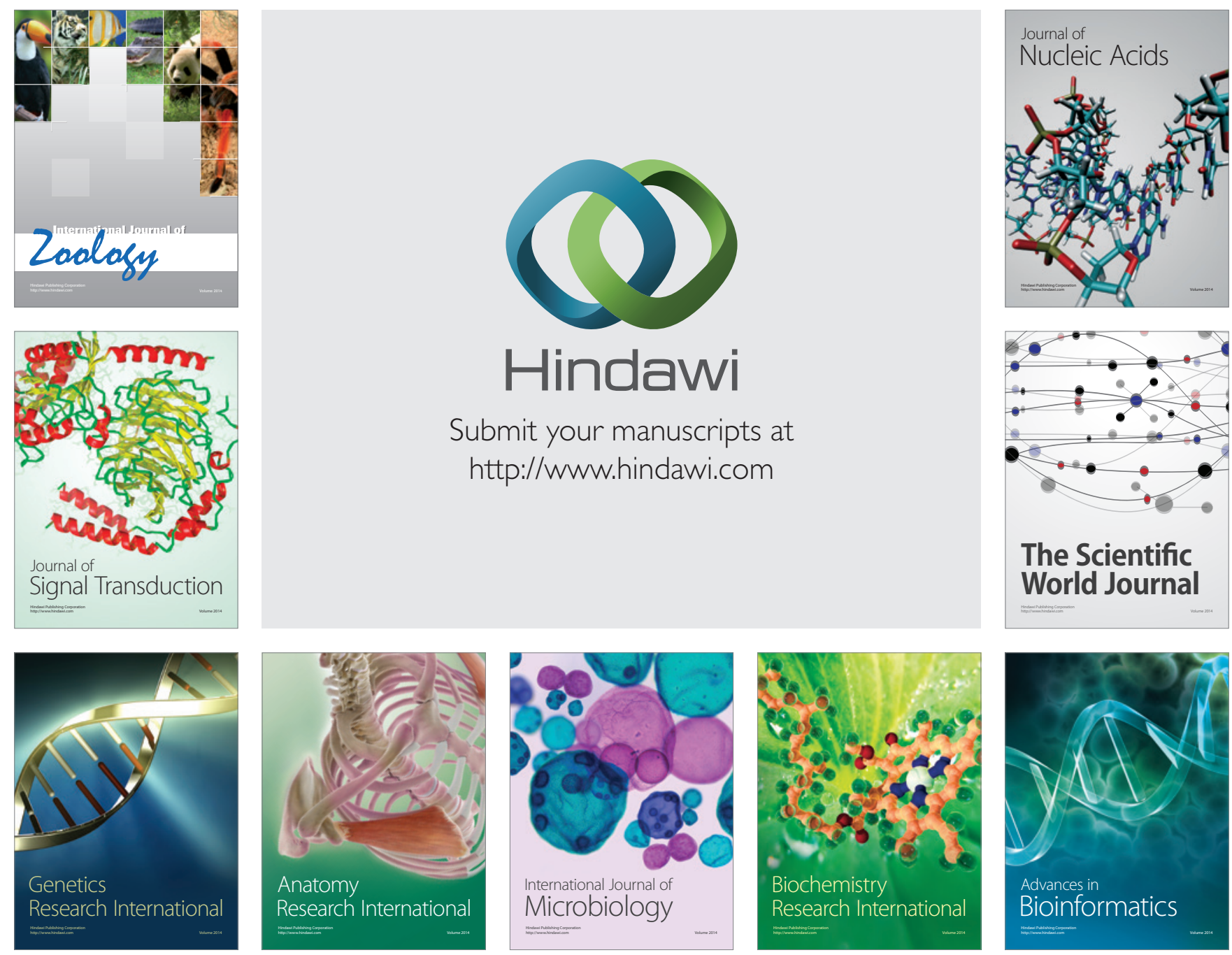

The Scientific World Journal
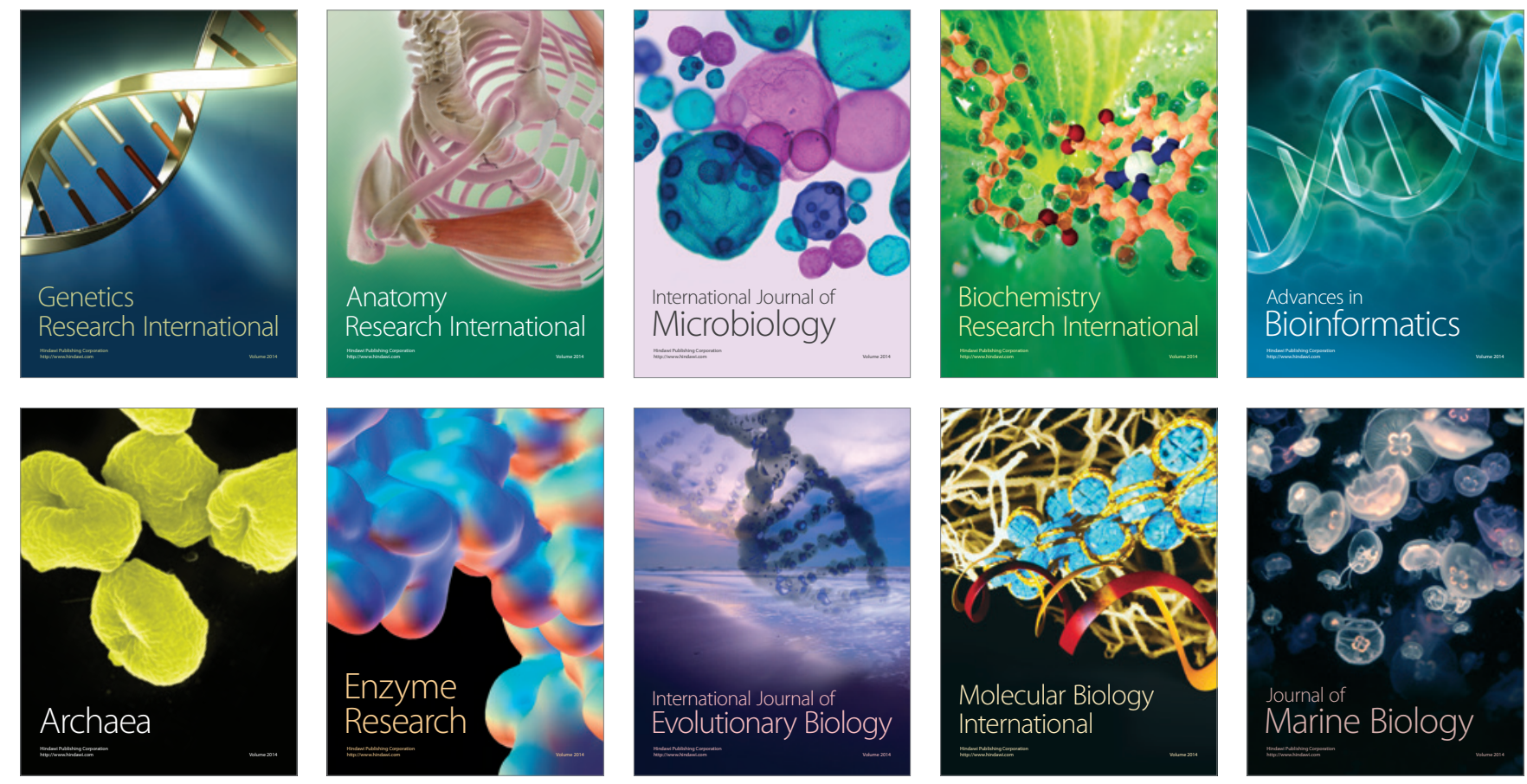